\title{
SINTERING OF THE TOP COAT IN THERMAL SPRAY TBC SYSTEMS UNDER SERVICE CONDITIONS
}

\author{
J.A.Thompson, W.Ji, T. Klocker and T.W.Clyne \\ Department of Materials Science \& Metallurgy \\ Cambridge University \\ Pembroke Street \\ Cambridge CB2 3QZ, UK
}

\section{Background}

Improved reliability of Thermal Barrier Coating (TBC) systems, under conditions in which the temperature at the free surface may be required to reach values as high as $1400^{\circ} \mathrm{C}$, is a critical aim for the next generation of gas turbine engines. It is now becoming clear that a significant contributory factor in the tendency for top coat spallation to occur in TBC systems during service is related to sintering effects in the zirconia top coat. There is already evidence(1) that the stiffness of detached top coats can rise substantially during heat treatments, even after relatively short periods at temperatures as low as about $1100-1200^{\circ} \mathrm{C}$. This increase in stiffness will lead to enhanced differential thermal contraction stresses during subsequent temperature changes and hence to an increase in the driving force for detachment of the coating(2). It seems likely that this phenomenon is at least partially responsible for many of the observed cases of debonding during service.

\section{Part I - Conventional Plasma-Sprayed Coatings}

It has been proposed(1) that stiffening can occur in thermally sprayed coatings, at temperatures well below those needed for conventional consolidation of zirconia powder compacts, as a consequence of certain features of the as-deposited structure. This consists of overlapping splats, with microcrack networks within individual splats and relatively poor inter-splat bonding. Strengthening of inter-splat bonds and healing of microcracks can occur as a consequence of local diffusional processes, with diffusion distances appreciably shorter than those necessary to allow a powder compact to consolidate.

A factor which has hitherto received little attention is the effect of the stress state in the top coat on its sintering behaviour. In particular, it might be expected that the presence of in-plane tensile stresses in the top coat would inhibit stiffening by opening up microcracks and preventing the diffusional transport across them expected to be necessary for the crack healing process. There is thus interest both in experimental measurement of stiffening behaviour in the presence of defined stress levels within the top coat and in simulation of the stress state under service conditions. In this paper, an experimental investigation is made of the sintering characteristics with and without the top coat adhering to the substrate. A previously-developed numerical process model(3-5) is used to predict the effect of the imposition of a thermal gradient through the system.

\section{Experimental Procedures}

\section{Plasma Spraying}

TBC systems were produced using a Plasma Tech Vacuum Plasma Spray (VPS) System. Bond coats $(\sim 100 \mu \mathrm{m})$ were sprayed at low pressure, while $\mathrm{ZrO}_{2}-8 \mathrm{wt} \% \mathrm{Y}_{2} \mathrm{O}_{3}$ top coats $(\sim 400 \mu \mathrm{m})$ were air plasma sprayed (APS). Nimonic 80A substrates (thickness $=$ $1.24 \mathrm{~mm}$ ) were used. Powder compositions and spray parameters are given in Tables I and II.

Table II: Plasma spray parameters for bond coat and top coat powder deposition.

\begin{tabular}{|c|c|c|}
\hline Material & CoNiCrAlY & $\begin{array}{c}\text { Zirconia - } \\
8 \text { wt \% } \mathrm{Y}_{2} \mathrm{O}_{3}\end{array}$ \\
\hline \hline Spray type & VPS & APS \\
\hline Spray distance (mm) & 270 & 120 \\
\hline Arc current (A) & 500 & 500 \\
\hline Voltage (V) & 55 & $60-70$ \\
\hline Ar flow rate (SLPM ${ }^{\dagger}$ ) & 50 & 80 \\
\hline $\mathrm{H}_{2}$ flow rate (SLPM & \\
\hline Gun speed (mm s) & 10 & 18 \\
\hline Chamber pressure & 200 mbar & atmospheric \\
\hline $\begin{array}{c}\text { Nozzle diameter } \\
\text { (mm) }\end{array}$ & 8 & 8 \\
\hline
\end{tabular}

${ }^{\dagger}$ SLPM $=$ Standard litres per minute

\section{Specimen Heat Treatment}

Free-standing top coat samples were heat treated in air at temperatures in the range $1000-1400^{\circ} \mathrm{C}$. A Lenton UAF $15 / 5$ furnace was used for this purpose. TBC samples with the substrate attached were sealed in Argon filled silica tubes prior to heat treatment, in order to reduce oxidation of the metallic components. Top coat removal was achieved by immersion in a bath of warm IICl.

Table I: Composition (by weight) of powders for plasma spraying.

\begin{tabular}{|c|c|c|c|c|c|c|c|c|c|c|}
\hline $\begin{array}{c}\text { System } \\
\text { Component }\end{array}$ & \multicolumn{10}{|c|}{ Content by wt\% } \\
\hline \hline & Material & $\mathrm{Ni}$ & $\mathrm{Co}$ & $\mathrm{Cr}$ & $\mathrm{C}$ & $\mathrm{Ti}$ & $\mathrm{Al}$ & $\mathrm{Y}$ & $\mathrm{ZrO}_{2}$ & $\mathrm{Y}_{2} \mathrm{O}_{3}$ \\
\hline \hline Substrate & Nimonic $80 \mathrm{~A}$ & $\mathrm{bal}$ & - & 19.5 & 0.06 & 2.4 & 1.6 & - & - & - \\
\hline Bond coat & CoNiCrAlY & 32 & bal & 21 & - & - & 8 & 0.5 & - & - \\
\hline Top coat & PSZ & - & - & - & - & - & - & - & bal & 8 \\
\hline
\end{tabular}




\section{Cantilever Bend Testing}

Coating stiffness was measured using a cantilever bend arrangement on detached top coats, using a scanning laser extensometer (Lasermike) to establish the beam deflection (Figure 1). The Young's modulus can then be deduced from the load / displacement plot using Equation 1, where I is the sample second moment of area and $\mathrm{y}$ is the measured deflection.

$$
E=\frac{P}{y I}\left\{\frac{L x^{2}}{2}-\frac{x^{3}}{6}\right\}
$$

Equation 1

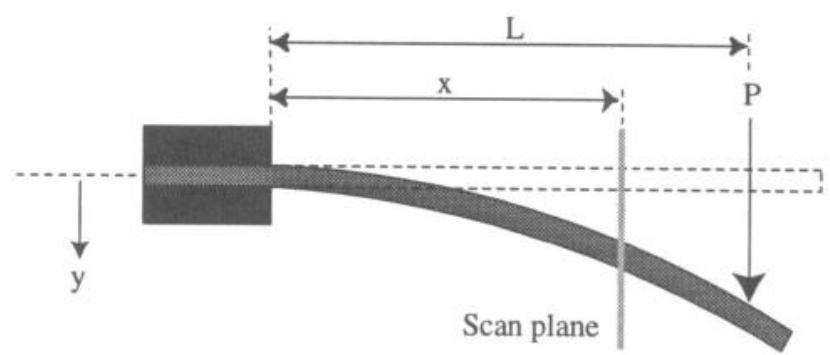

Figure 1: Experimental arrangement for the measurement of coating Young's modulus by cantilever bend technique.

\section{Results}

\section{Eree-standing coatings}

The data in Figure 2 show that, while the stiffness of assprayed top coats is typically about $10 \mathrm{GPa}$, this approximately doubles after a few hours at temperatures as low as $1100^{\circ} \mathrm{C}$. The low Young's modulus of the as-sprayed top coat is attributed to the presence of a large number of flaws in the sprayed microstructure, in particular interlamellar pores and through thickness microcracks (Figures 4 and 5).

While little further increase in stiffness occurs with holding at $1100^{\circ} \mathrm{C}$, a further progressive rise, to values of the order of 60 $70 \mathrm{GPa}$, occurs at $1300-1400^{\circ} \mathrm{C}$. The initial sharp increase is attributed to improvements in inter-splat bonding, whereas progressive rise is a consequence of microcrack healing.

Figure 3 illustrates the proposed sintering mechani schematically. At low temperatures, only defects with a sn separation can be healed (i.e interlamellar pores where mate from adjacent splats is in very close contact). At temperature: excess of $1200^{\circ} \mathrm{C}$, however, diffusion starts to occur considera more rapidly and the healing of larger defects (through thickn microcracks) becomes possible. The nature of the spra: microstructure, with two relevant flaw types, thus results in two stage stiffening observed in Figure 2. The stiffness chan measured will result in higher stress levels in the ceramic top c after exposure to high temperature. This, in turn, raises interfacial strain energy release rate, the driving force for top c debonding and means that the probability of coating failure increased(6).

Microstructures illustrating the proposed sequence of sinter are shown in Figures 6-9. Note that after 100 hours at 1100 microcrack healing is not observed (Figure 7), but there evidence of grain growth across splat boundaries (Figure giving Stage I stiffening. However, after a similar period of ti at $1300^{\circ} \mathrm{C}$, both mechanisms are observed (Figures 8 and 9).

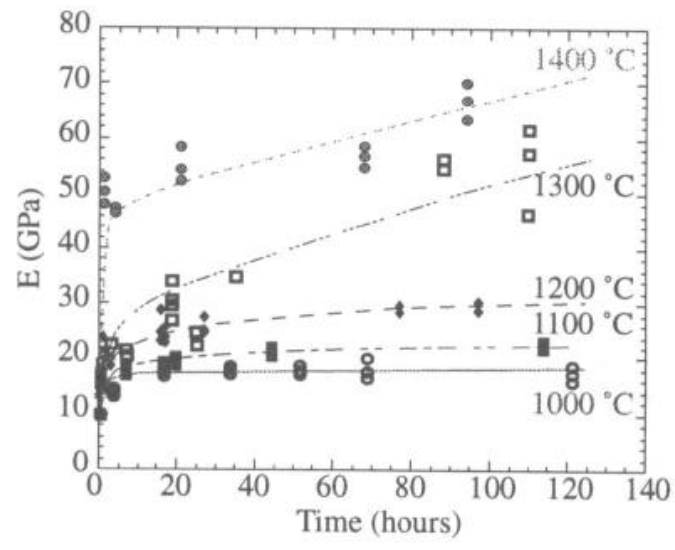

Figure 2: Measured stiffness changes of PSZ top coats after h treatment (detached from the substrate) at various temperatures.

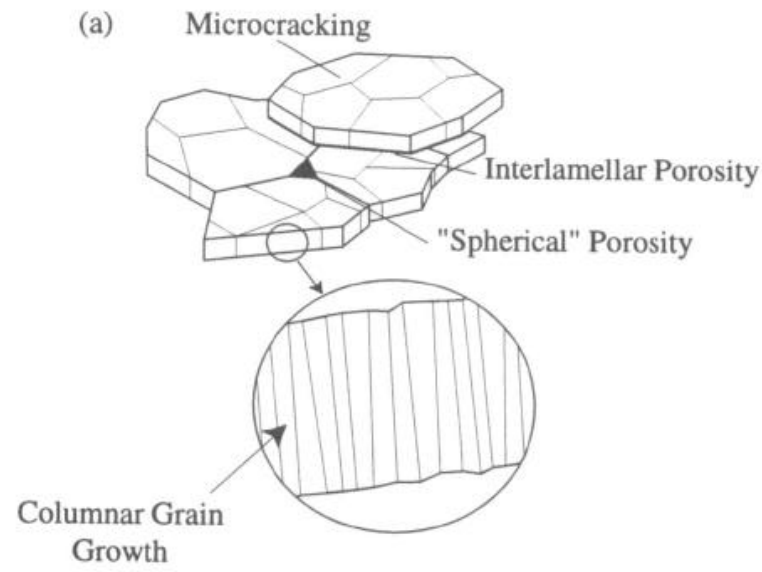

(b) STAGE I STIFFENING

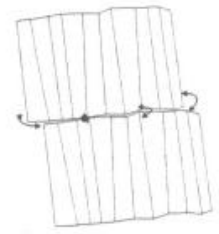

(c) STAGE II STIFFENING

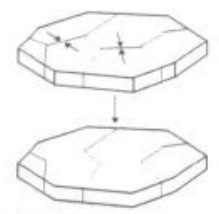

Figure 3: Schematic representation of the proposed stiffening mechanism occurring at high temperarure. The as-sprayed microstructu incorporates three types of pore, (a). Stage I stiffening (b) involves healing of interlamellar porosity, where the separation betwe material is very small, while at longer times and at higher temperature, Stage II stiffening (c) occurs by microcrack healing. 


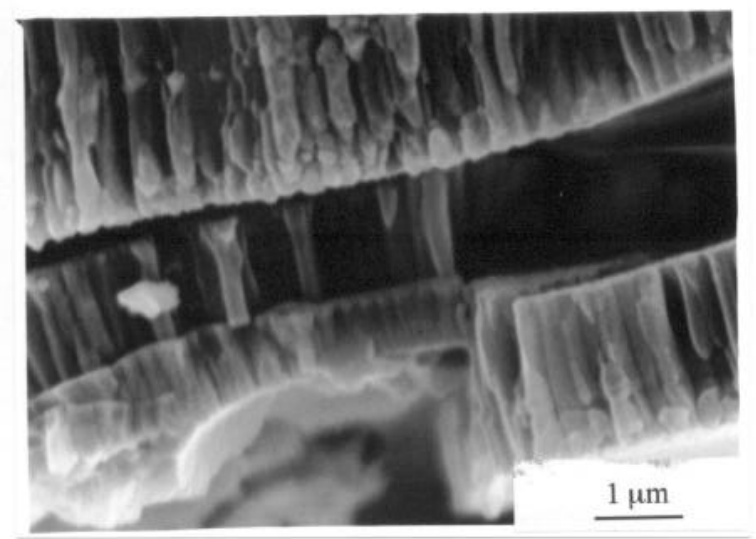

Figure 4: SEM micrograph of the fracture surface of APS-PSZ in the as-sprayed condition.

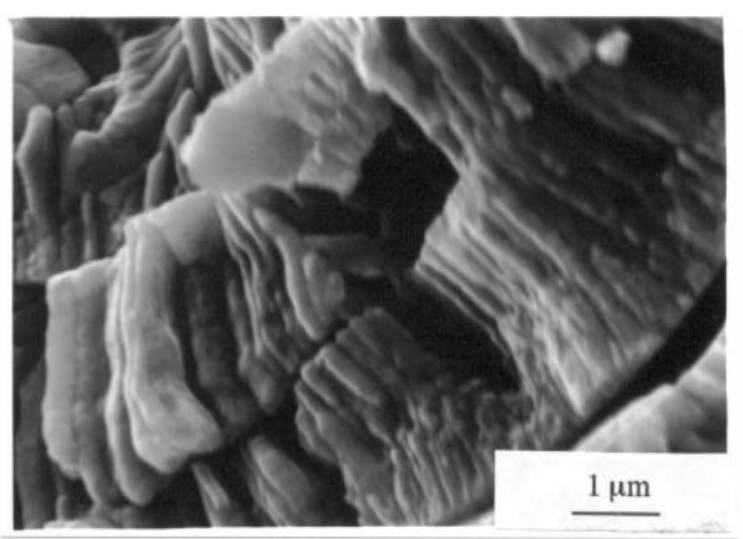

Figure 6: SEM micrograph showing the fracture surface of APSPSZ after 100 hours at $1100^{\circ} \mathrm{C}$. Note where grain growth has occurred across splat boundaries.

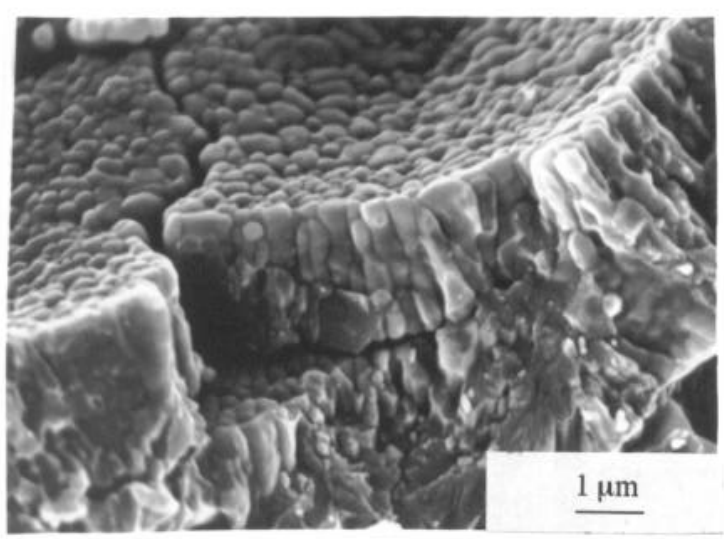

Figure 8: SEM micrograph of the fracture surface of APS-PSZ after 114 hours at $1300^{\circ} \mathrm{C}$. Again note where grain growth has occurred across splat boundaries.

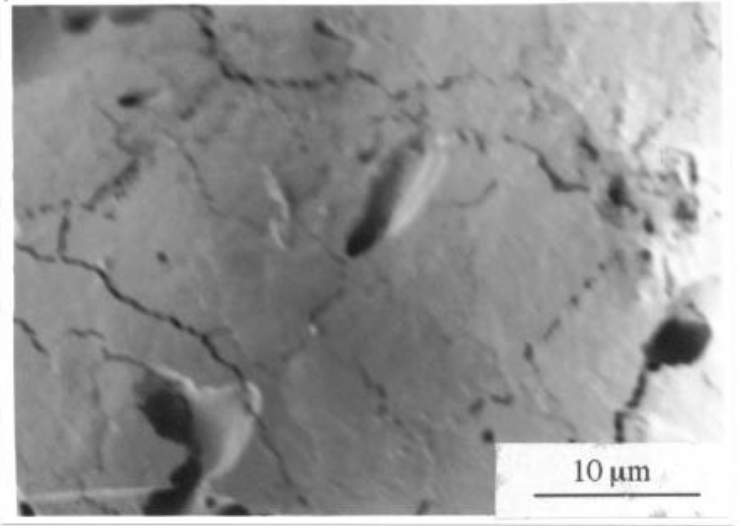

Figure 5: SEM micrograph showing the network of microcracks on the top surface of as-sprayed APS- PSZ.

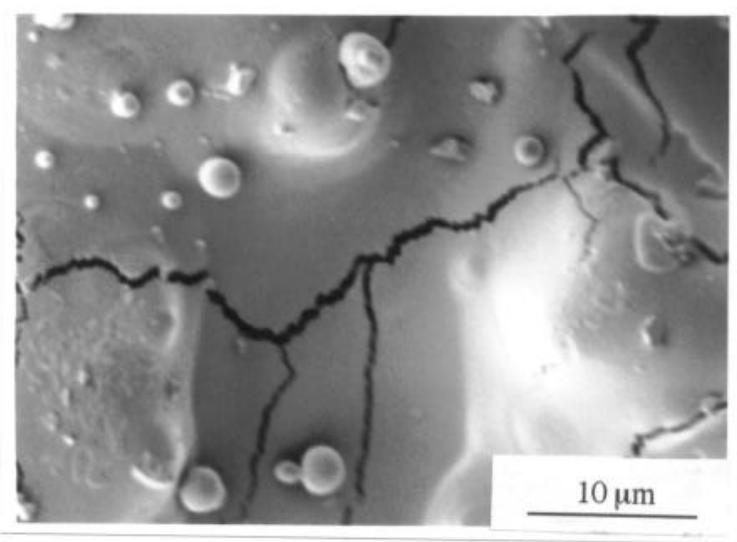

Figure 7: SEM micrograph of the free surface of APS-PSZ after 100 hours at $1100^{\circ} \mathrm{C}$. There is no evidence of microcrack closure.

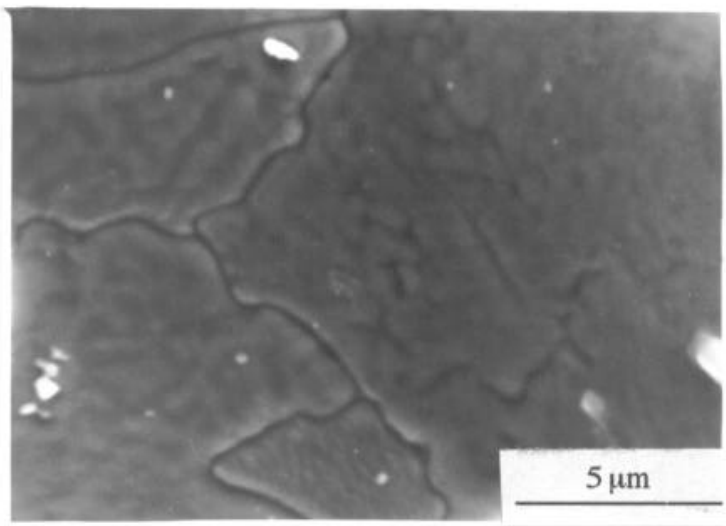

Figure 9: SEM micrograph of the free surface of APS-PSZ after 114 hours at $1300^{\circ} \mathrm{C}$. Microcrack closure can be clearly seen. 


\section{Attached Coatings}

The preceding results apparently indicate that the stiffness of the top coat can rise very sharply during relatively short periods of exposure to temperatures of the order of $1200-1300^{\circ} \mathrm{C}$, which would be expected to cause substantial increases in the driving force for debonding as differential thermal contraction stresses rise during subsequent cooling. However, repetition of the cantilever bend test measurements, for specimens which remained attached to the substrates during the heat treatment, revealed that the rates of stiffening were thereby significantly reduced (Fig. 10).

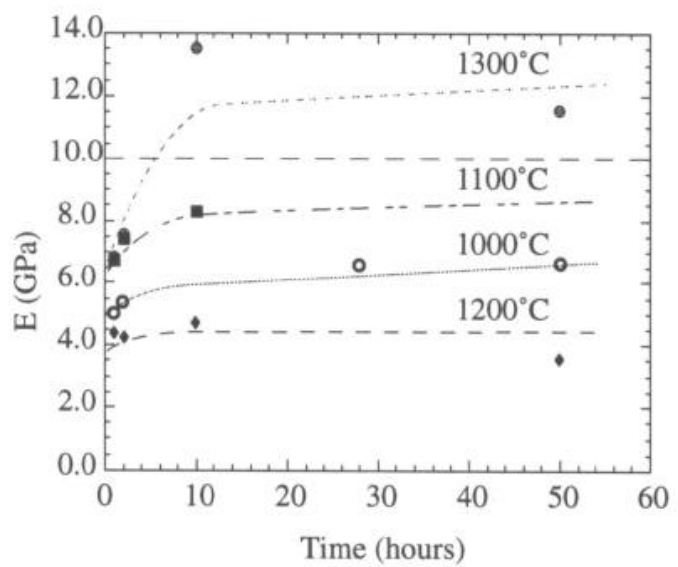

Figure 10: Variation in (room temperature) top coat Young's modulus after various heat treatments (coating attached to substrate during exposure to high temperature).

On comparing these data with those in Figure 2, it is clear that, not only has the presence of the substrate reduced the rate of top coat stiffening, but the heat treatment has actually generated a reduction in the Young's modulus after treatment at low temperature and for short times at the higher temperature $\left(1300^{\circ} \mathrm{C}\right)$. It is concluded that, due to the higher coefficient of thermal expansion of the metallic substrate and bond coat, microcracks are held open at elevated temperatures. Thus it becomes clear that the sintering kinetics are a function, not only of the holding temperature and top coat microstructure, but also of the stress state at temperature. This is in principle an unsurprising result, since compressive stress is often applied to powder compacts in commercial sintering operations in order to increase the rate of densification(7), although the magnitude of the effect in this case is certainly striking.

There may be some growth of microcracks in tension, or sintering may occur at temperature such that the cracks becoming locked in in the open position, resulting is a more compliant structure upon cooling to room temperature. Evidence for this is seen in Figure 11 , where, in addition to the usual microcracking pattern, a wider crack can also be seen. The presence of such defects will act to reduce the coating stiffness.

However, at higher temperatures $\left(1300^{\circ} \mathrm{C}\right)$, the coating stiffness increases to a level above that found in the as-sprayed coating. Due to the increased rate of diffusional processes at such temperatures, sintering can apparently start to raise the coating stiffness. Evidence of microcrack healing is seen in Figure 12.

\section{Numerical Modeling}

A limitation of the experimental procedure used in this study is that the sample is isothermal during heat treatment. This shoulc be contrasted with the in-service conditions, when the presence o cooling air channels within the blade, and high incident hea fluxes on the free surfaces, results in pronounced throughthickness thermal gradients within the top coat during most of the time spent at elevated temperatures. Such conditions are very difficult to recreate in the laboratory. However, it is important to examine the likely effect of such temperature gradients.

A previously-developed numerical model(3-5) was used tc explore the expected stress distributions in service, with and without an imposed thermal gradient. The results of these simulations are shown in Figures 13 and 14. It can be seen tha the presence of the substrate leads to a tensile stress of abou $40 \mathrm{MPa}$ for the isothermal case, but this is reduced to a range of about $20 \mathrm{MPa}$ (free surface) to $30 \mathrm{MPa}$ (at interface with bond coat) when the through-thickness thermal gradient is introduced.

That such stresses are expected to have a significant effect on sintering of these coatings can be deduced by recognising that they will generate strains of the order of a few millistrain, thus opening microcracks spaced a few tens of microns apart by increments of the order of $0.1 \mu \mathrm{m}$. Since observed typical crack opening flank separations at room temperature are around $0.1 \mu \mathrm{m}$, this change is expected to be significant in terms of inhibiting microcrack healing.

However, for the case in which a thermal gradient was imposed the top coat stresses are reduced significantly in comparison with the isothermal case, particularly at the free surface. It is expectec therefore, that the rate of sintering (and thus stiffening) will be fastest at the free surface of the top coat. This is not only due to the higher temperature there, but also to the reduced tensile stress levels arising as a result of the thermal gradient. In order to investigate experimentally the sintering kinetics of the top coat in this regime, using an isothermal arrangement, it would apparently be necessary to either artificially apply a stress of $20 \mathrm{MPa}$ to a detached coating during the heat treatment or to use a substrate having a lower mismatch in thermal expansivity with the top coat.

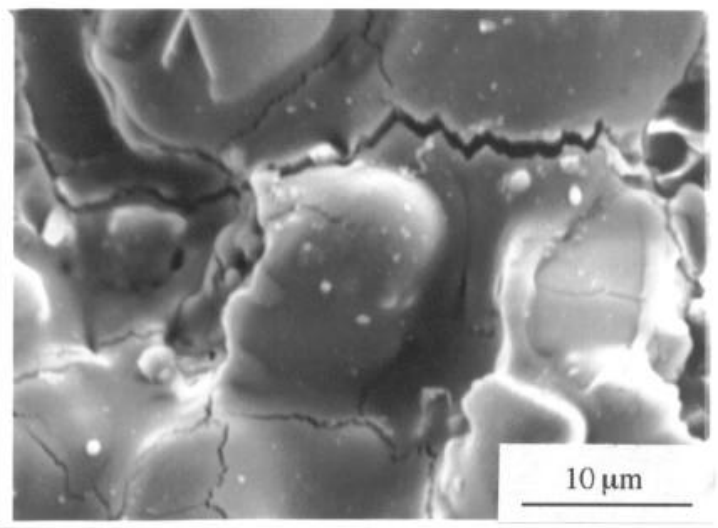

Figure 11: APS zirconia coating after 10 hours at $1100^{\circ} \mathrm{C}$. Note how the crack opening displacement has apparently increased for at least one of the microcracks after heat treatment, as a consequence of the tensile stresses present at high temperatures. 


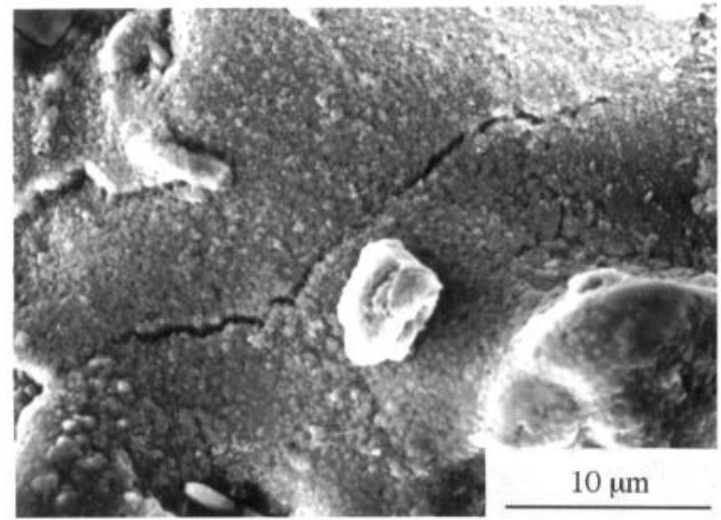

Figure 12: APS zirconia coating after 50 hours at $1300^{\circ} \mathrm{C}$. Note the partial healing of microcracks which has occurred.

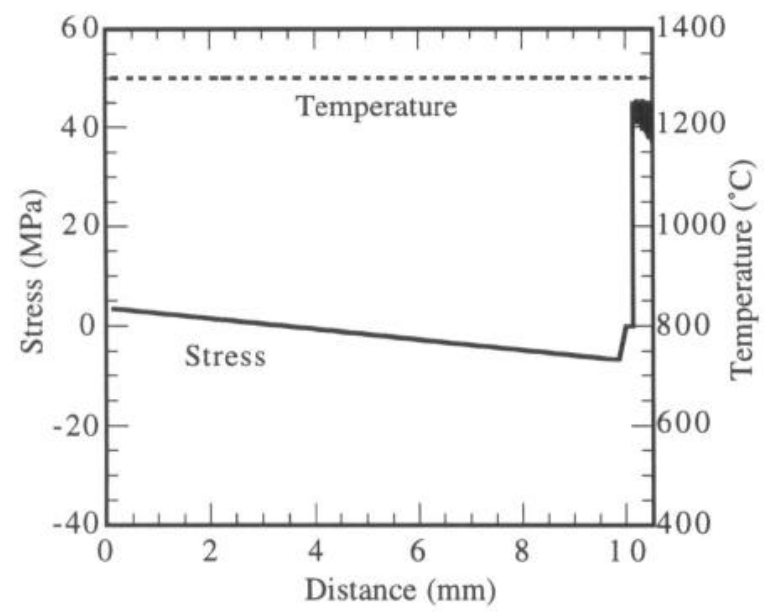

Figure 13: Predicted through-thickness stress (and temperature) distribution for a TBC system after 5 minutes spent at $1300^{\circ} \mathrm{C}$ (isothermal heating).

\section{Part II - Co-spraying of dense and hollow $\mathrm{ZrO}_{2}$ powder particles}

\section{Background}

There is thus considerable interest in the production of coatings which are, not only relatively compliant, but also resistant to stiffening during prolonged exposure to elevated temperature. Of course, some factors are known to promote sintering. These include the presence of various impurities $(8,9)$, particularly those which generate low melting point segregate material (e.g. silica). Use of high purity powders is likely to lead to at least some improvement in sintering resistance, but this approach may be unacceptable in terms of the associated economic penalties. The development of microstructures which are inherently less susceptible to sintering is a more attractive concept. This requires

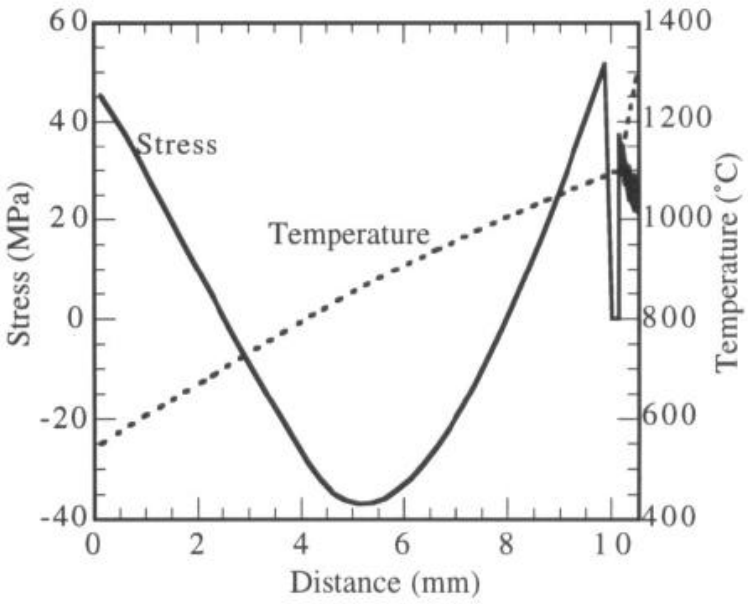

Figure 14: Predicted through-thickness stress and temperature distribution obtained with an increase in the inputted rear face heat transfer coefficient.

\section{Conclusions}

It has been shown that the conventional air plasma sprayed micrstructure exhibits desirable strain tolerance (low stiffness) in the as-sprayed state, largely as a result of the network of small defects present. However, it has also been shown that healing of these flaws at typical service temperatures can significantly reduce the strain tolerance of the coating, raising the likelihood of top coat spallation. The presence of the substrate during high temperature exposure has been shown to hinder the sintering process, but it is still considered likely than top coat sintering can play an important role in the in-service failure of thermal barrier coatings.

that the mechanisms by which stiffening occurs in conventional thermally sprayed coatings should be identified. This has been addressed in recent publications $(1,10)$. It was concluded that the processes primarily responsible for stiffening are: (a) locking together of poorly-bonded overlapping splats and (b) healing of the network of microcracks which forms within each splat during deposition. The type of microstructural feature which is expected to confer a high compliance and resistance to stiffening is relatively large scale pores(11), without the regions of high interfacial curvature which promote rapid local sintering. 


\section{Experimental Procedures}

\section{Plasma spraying}

TBC systems were produced by vacuum plasma spraying of a CoNiCrAlY bond coat $(\sim 100 \mu \mathrm{m})$ and a $\mathrm{ZrO}_{2}-8 \mathrm{wt} \% \mathrm{Y}_{2} \mathrm{O}_{3}$ top coat $(\sim 400 \mu \mathrm{m})$ onto Nimonic $80 \mathrm{~A}$ substrates (thickness $=1.24 \mathrm{~mm}$ ). Spray deposition of the top coat was carried out both using conventional, fully dense zirconia powder particles, of about $20 \mu \mathrm{m}$ diameter, and also by co-spraying this powder with larger $(60 \mu \mathrm{m})$, highly porous particles (Figure 15$)$. Co-spraying was performed by VPS in order to increase the probability of collisions between molten $\mathrm{ZrO}_{2}$ particles and unmelted hollow spheres. Under suitable conditions (Table III), this resulted in deposit microstructures exhibiting relatively large pores, associated with the presence in the spray cone of the large, porous particles.

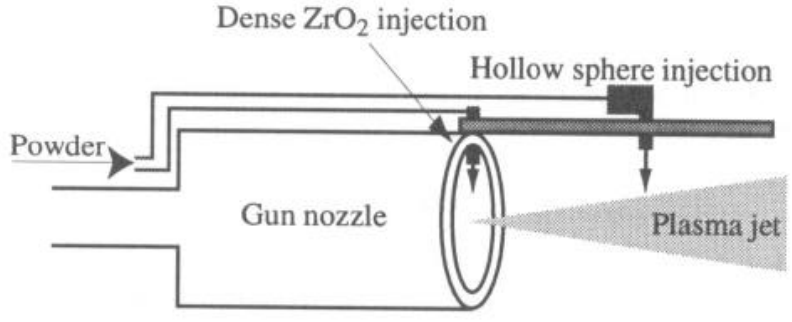

Figure 15: Schematic representation of the powder injection positions for co-spraying of dense and hollow zirconia powder particles.

Table III: Plasma spray parameters for co-spraying of dense and hollow zirconia particles.

\begin{tabular}{|c|c|c|}
\hline Material & $\begin{array}{c}\mathrm{ZrO}_{2}-8 \mathrm{wt} \% \mathrm{Y}_{2} \mathrm{O}_{3} \\
\text { (Dense particles) }\end{array}$ & $\begin{array}{c}\mathrm{ZrO}_{2}-8 \mathrm{wt} \% \mathrm{Y}_{2} \mathrm{O}_{3} \\
\text { (Hollow spheres) }\end{array}$ \\
\hline $\begin{array}{c}\text { Powder feed rate } \\
\text { (\%max) }\end{array}$ & 15 & 45 \\
\hline $\begin{array}{c}\text { Average particle } \\
\text { size (m) }\end{array}$ & 20 & 60 \\
\hline Spray type & \multicolumn{2}{|c|}{ VPS } \\
\hline $\begin{array}{c}\text { Chamber pressure } \\
\text { (mbar) }\end{array}$ & 330 & 300 \\
\hline $\begin{array}{c}\text { Spray distance } \\
\text { (mm) }\end{array}$ & \multicolumn{2}{|c|}{600} \\
\hline Arc current (A) & \multicolumn{2}{|c|}{60} \\
\hline Voltage (V) & \multicolumn{2}{|c|}{60} \\
\hline $\begin{array}{c}\text { Ar flow rate } \\
\left.\text { (SLPM }{ }^{\dagger}\right)\end{array}$ & \multicolumn{2}{|c|}{15} \\
\hline $\begin{array}{c}\text { N2 flow rate } \\
\text { (SLPM }\end{array}$
\end{tabular}

${ }^{+}$SLPM $=$Standard litres per minute

\section{$\underline{\text { Results }}$}

\section{As-sprayed microstructure}

Co-spraying of dense and hollow powders produced coatings with very different microstructures to those exhibited by conventional plasma-sprayed coatings (Figure 16). It can be seen that the regular lamellar "splat" structure has been disrupted. This is believed to be due to the high proportion impacting unmelted or partially melted hollow particles. Although some intact hollow spheres are trapped in the coating (Figure 17), it was more common to find fragments of broken particles which remained in the coating. The result of this is to raise the overall porosity of the coating. The typical defect size is also increased. It is likely that this will have an effect upon the rate of stiffening due to sintering processes. It should, however, be mentioned that the suitability of such a microstructure with regard to other properties (thermal conductivity, erosion resistance) would require attention before its use could be seriously considered in practice.

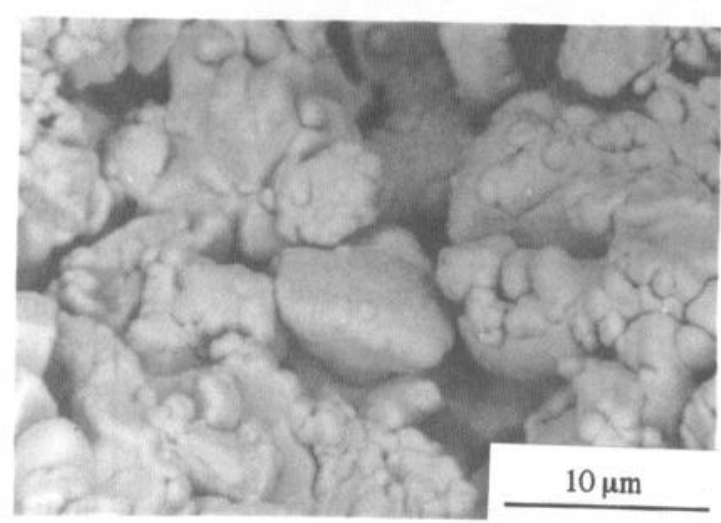

Figure 16: SEM micrograph showing typical morphology and distribution of porosity in the co-sprayed deposits.

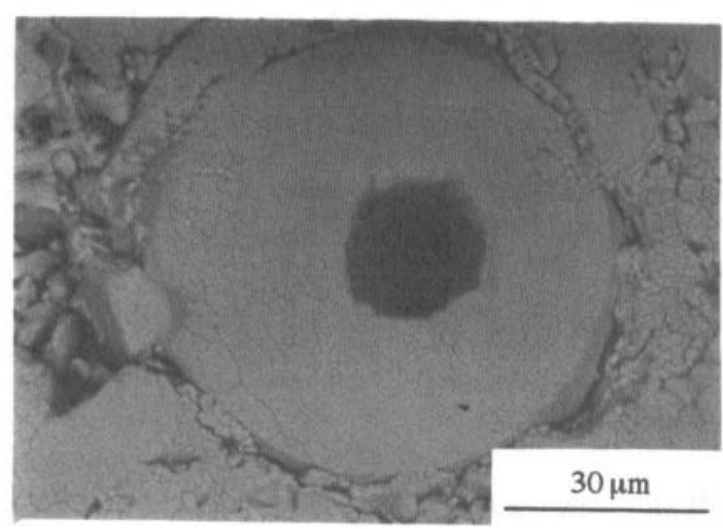

Figure 17: SEM micrograph of a polished top coat cross section for a co-sprayed deposit, illustrating the incorporation of a hollow zirconia particle in the coating.

\section{Co-sprayed Coating Stiffness}

An indication of the stiffening characteristics is given in Figure 18. It can be seen that (a) the stiffness of the as-sprayed co-spray material $(\mathrm{E} \sim 5-15 \mathrm{GPa})$ is appreciably lower than that of the conventionally-produced coatings $(\mathrm{E} \sim 10-30 \mathrm{GPa})$ and $(\mathrm{b})$ the rate of stiffening during heat treatment is considerably lower for the co-sprayed material, at least for the temperatures studied. 


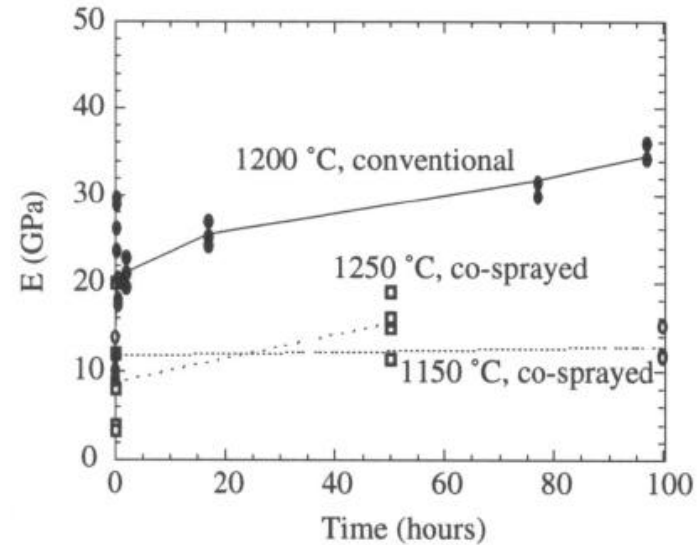

Fig.18 Measured Young's modulus values for $\mathrm{ZrO}_{2}-8 \mathrm{wt} \% \mathrm{Y}_{2} \mathrm{O}_{3}$ coatings, produced either by conventional spraying or by cospraying of dense and hollow powder particles, after heat treatments at different temperatures, carried out while detached from the substrate.

These improvements in the high temperature sintering behaviour of plasma sprayed thermal barrier layers are due to the microstructural changes described. Typical pore sizes in the cosprayed material are of the order of a few microns, while in conventional plasma-sprayed coatings, microcrack opening (in the as-sprayed state) are of the order 0.1-1 $\mu \mathrm{m}$, while interlamellar distances may be much less than this. Clearly, the healing of such large defects requires the transport of large amounts of material over long distances. However, there is evidence of such processes occurring. Figure 19 shows sintering necks present in a sample heat treated at $1150^{\circ} \mathrm{C}$ for 100 hours. These necks will lock up the structure in the same way as microcrack closure and interlamellar pore healing in conventional plasma-sprayed coatings.

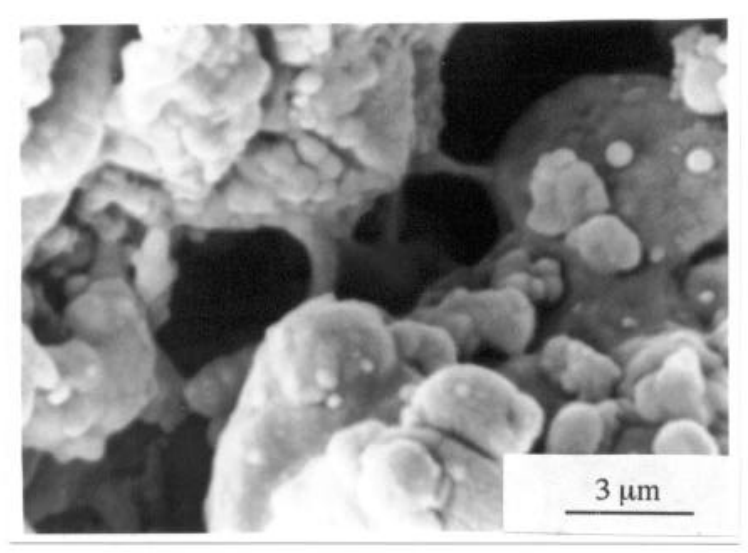

Figure 19: SEM micrograph showing sintering necks in a cosprayed $\mathrm{ZrO}_{2}-8 \mathrm{wt} \% \mathrm{Y}_{2} \mathrm{O}_{3}$ coating.

However, the increases in stiffness exhibited by co-sprayed coatings are much lower than those shown by the conventionally sprayed material. A preliminary attempt has been made to model this effect. Using the diffusion coefficient data of JiminezMelendo et al(12), for cubic $\mathrm{ZrO} 2-8 \mathrm{wt} \% \mathrm{Y}_{2} \mathrm{O}_{3}$, the $\sqrt{D t}$ diffusion distances can be calculated and compared with typical microstructural defect sizes (Figure 20). A grain size of $2 \mu \mathrm{m}$ and grain boundary thickness of $1 \mathrm{~nm}$ were assumed. These diffusion distances are comparable with the defect sizes observed in the sprayed microstructures, and it is clear that the increase in pore size observed in the as-sprayed material is likely to result in a significant increase in the maximum operating temperature of the material. However, the data should be treated with some caution, since the diffusion coefficients used apply to the cubic zirconia system, rather than the metastable tetragonal phase which predominates in the plasma-sprayed material.

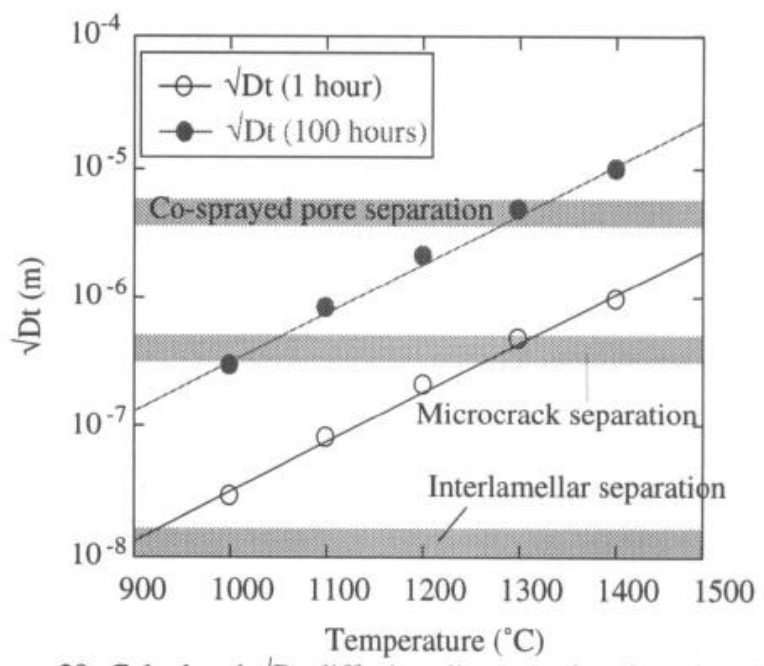

Figure 20: Calculated $\sqrt{ } \mathrm{Dt}$ diffusion distances for zirconium ions in $\mathrm{ZrO}_{2}$ (including contributions from both grain boundary and lattice diffusion), compared with typical defect sizes.

\section{Conclusions}

Co-spraying of dense and hollow zirconia powder particles, with a downstream injection position for the hollow spheres has resulted in the deposition of a novel top coat micrstructure. Some intact hollow particles are incorporated into the coating, but most break up on impact. The pore distribution is altered significantly in the co-sprayed material, with a higher density of larger flaws.

The stiffening behaviour of the new material shows an improvement over the conventional plasma sprayed material as a result of the new pore distribution. However, some sintering is observed and the growth of necks can be seen over quite large distances $(>1 \mu \mathrm{m})$ after moderate high temperature exposure $(100$ hours, $1150^{\circ} \mathrm{C}$ ).

The deposition of novel microstructures for improved resistance to high temperature stiffening by sintering mechanisms has shown some promising preliminary results. However, a greater understanding of the precise mechanisms controlling top coat sintering is required, particularly with regard to the role of coating impurities. In addition, the suitability of such microstructures for use in an engine environment needs addressing. For example, a microstructure exhibiting increased sintering resistance would be of limited use if it were accompanied by a reduction in erosion resistance or a dramatically increased thermal conductivity. 


\section{References}

1. J. A. Thompson and T. W. Clyne, "The Stiffness of Plasma Sprayed Zirconia Top Coats in TBCs", in United Thermal Spray Conference (1999), Dusseldorf, E. Lugscheider and P. A. Kammer (Eds.), DVS, 835-840.

2. T. W. Clyne and S. C. Gill, "Residual Stresses in Thermally Sprayed Coatings and their Effect on Interfacial Adhesion - A Review of Recent Work", J. Thermal Spray Technol., 5 (1996), 118.

3. S. C. Gill and T. W. Clyne, "Stress Distributions and Material Response in Thermal Spraying of Metallic and Ceramic Deposits", Met. Trans., 21B (1990), 377-385.

4. Y. C. Tsui, S. C. Gill and T. W. Clyne, "Simulation of the Effect of Creep on the Stress Fields during Thermal Spraying onto Titanium Substrates", Surf. Coat. Technol., 64 (1994), 61-68.

5. S. C. Gill and T. W. Clyne, "Investigation of Residual Stress Generation during Thermal spraying by Continuous Curvature Measurement", Thin Solid Films, 250 (1994), 172-180.

6. J. A. Thompson, W. Ji and T. W. Clyne, "The Effect of Top Coat Sintering on Ceramic Spallation in Plasma-Sprayed Thermal Barrier Coatings", in 13th Int. Conf. on Surface Modific. Techn.(SMT XIII) (1999), Singapore, K. A. Khor (Ed.) NTU, in press.

7. W. D. Kingery, H. K. Bowen and D. R. Uhlmann, Introduction to Ceramics, Wiley and sons, 1976), Pages

8. M. Verkerk, A. Winnubst and A. Burggraaf, "Effect of Impurities on Sintering and Conductivity of Yttria-Stabilised Zirconia", J Mat Sci, 17 (1982), 3113-3122.

9. H. E. Eaton and R. C. Novak, "Sintering Studies of Plasma Sprayed Zirconia", Surf. Coat. Technol., 32 (1987), 227-236.

10. J. Ilavsky, G. G. Long and A. J. Allen, "Evolution of the Microstructure of Plasma Sprayed Deposits During Heating", in !5th International Thermal Spray Conference (1998), Nice, France, C. Coddet (Ed.) Vol. 2, ASM International, 1641-1644.

11. J. L. Shi et al., "Sintering Behavior of Fully Agglomcrated Zirconia Compacts", J.Am. Ceram. Soc., 74(5) (1991), 994-997.

12. M. Jimenez-Melendo et al., "Cation Lattice Diffusion in Yttria-Stabilized Zirconia deduced from Deformation Studies", Materials Science Forum, 239-241 (1997), 61-64. 